\title{
VISCOMETRIC INVESTIGATIONS AND MOLECULAR INTERACTIONS OF SOME DERIVATIVES OF 5-SUBSTITUTED INDOLE DIHYDROPYRIMIDINES IN MIXED ORGANIC SOLVENTS
}

\author{
L. C. Heda, Rashmi Sharma, S. R. Mosalpuri and Pramod B. Chaudhari* \\ Research Laboratory, Dept. of Chemistry, S.D. Govt. College, Beawar, 305901, Rajasthan, (India). \\ *Corresponding author, Tel.: +919052168560 \\ E-mail:prmdchaudhari@yahoo.co.in
}

\begin{abstract}
Colloid chemical behavior of indole dihydropyrimidines in non-aqueous solvent mixture benzene-methanol of varying composition has been investigated by viscometric measurements at $303 \mathrm{~K} \pm 0.1$. The viscosity of the system increases with the increase in concentration. The Trend Change Point (TCP) values have been determined by intersection of two straight lines, which are found to be dependent on the composition of solvent mixtures. The study confirms that the nature of synthesized compounds agglomerate formed below and above $50 \%$ benzene concentration is quite different. The viscometric data have been analyzed in terms of Einstein, Vand, Moulik and Jones-Dole equations. These well known equations have been successfully applied to explain the results of viscosity measurements and the viscometric parameters show that the behavior of compound changes in the proximity of $50 \%$ benzene concentration.
\end{abstract}

Keywords: Substituted indoles, Dihydropyrimidines, Trend change point, viscosity, and Solute-Solvent interaction.

\section{INTRODUCTION}

In the family of heterocyclic compounds Nitrogen containing heterocycles are an important class of compounds in the medicinal chemistry and also contributed to the society from biological and industrial point which helps to understand life processes. ${ }^{1}$ This seems to be because pyrimidines represents one of the most active class of compounds possessing wide spectrum of biological activity viz. significant in vitro activity against unrelated DNA and RNA, viruses including polio herpes viruses, diuretic, antitumor, anti HIV, cardiovascular. ${ }^{2}$ Biginelli compounds show a diverse range of biological activities. The interest focused on
Biginelli compounds leading to the development of Nitractin, ${ }^{3}$ that has excellent activity against the virus of trachoma group, the same compounds also exhibit antibacterial activity. 4-Aryl dihydropyrimidines e.g. Nifedipine are the important and most studied class as Calcium channel modulars, in 1975 their introduction in clinical medicine for the treatment of cardiovascular diseases. ${ }^{4}$ some of the analogues were screened as antitumor agents.

Pyrimidine -5 -carboxamide of type was reported to possess anticarcinogenic activity, antiinflammatory, ${ }^{5}$ analgesic. ${ }^{6}$ The topsentins, as antiviral and antitumor agents from marine sponge represents the emerging class of bis indole alkaloids. During the search of bioactive natural pro- 
ducts act as cytotoxic and antifungal compounds belongs to class noprtopsentins. ${ }^{7}$ The presence of highly substituted indole and indolines in a variety of bioactive molecular targets has inspired a number of groups including ours to develop new and improved routes to their synthesis. ${ }^{8}$ Recently there is a much interest in the synthesis of small molecules for chemist in accelerating drug discovery. ${ }^{9}$

In the view of the potential applications of these compounds, present work has been undertaken to explain colloid chemical behavior in mixed solvents. Benzene and methanol has been chosen as the co solvents in the title study. The mixed solvents have a tendency to interact with compounds, which affect the aggregation of molecules. The viscosity data based on various equations has been extensively used to furnish information concerning the structural changes in solution trend change point (TCP) and nature of molecule-solvent interaction. This vital information plays an important role in their selection for various industrial and biological applications.

\section{EXPERIMENTAL}

The most obvious approach for carrying out the synthesis of substituted indole dihydropyrimidines is due to potent biological activity of indoles as well as dihydropyrimidines. The synthesis begins from the commercially available indole; we were able to synthesize 5-substituted indoles in three steps using known protocol. ${ }^{10}$ The further formylation with $\mathrm{DMF} / \mathrm{POCl}_{3}$ by Wismeyer - Hack method to obtain Indole 3-carboxaldehyde in good yields. ${ }^{11}$

In cyclocondensation reaction of indole carboxaldehyde, thiourea and ethylacetoacetate in the presence of acid catalyst by refluxing in ethanol to afford indole dihydropyrimidines (1). ${ }^{12}$

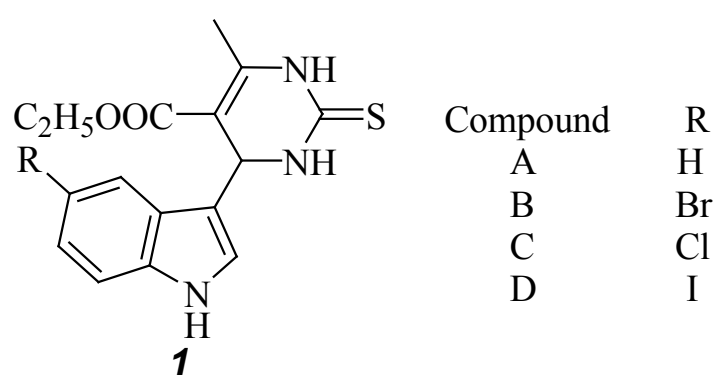

Correlating $1 \mathrm{H}$ NMR and IR data with data for corresponding compounds made the structural assignments for indole 3-carboxaldehydes and indole dihydropyrimidines. Solubility of compounds in benzene and methanol was determined by preparing solutions of compounds in solvents. The viscosity of the solutions was measured by Ostwald's viscometer in thermostat bath. The viscometer was calibrated frequently with distilled water.

\section{RESULTS AND DISCUSSION}

The flow of characterization of solutions in terms of viscometric measurements has been employed as a tool to find out the TCP of molecule in benzene - methanol mixtures. The viscosity of solutions of varying composition of benzene- methanol mixtures increases with the increase in the concentration. 
Table - 1.Viscosity, $\eta$, of compound A in benzene-methanol at $303 \mathrm{~K} \pm 0.1$ in poise

\begin{tabular}{ccccc}
\hline \multicolumn{5}{c}{ Volume \% of methanol } \\
\hline Conc & $40 \%$ & $60 \%$ & $80 \%$ & $100 \%$ \\
\hline 0.0002 & 0.589 & 0.566 & 0.549 & 0.529 \\
0.0004 & 0.604 & 0.581 & 0.561 & 0.541 \\
0.0006 & 0.616 & 0.593 & 0.570 & 0.551 \\
0.0008 & 0.620 & 0.599 & 0.574 & 0.553 \\
0.0010 & 0.627 & 0.604 & 0.580 & 0.557 \\
0.0012 & 0.634 & 0.612 & 0.585 & 0.561 \\
0.0014 & 0.643 & 0.619 & 0.589 & 0.564 \\
\hline
\end{tabular}

Table -2 . Viscosity, $\eta$, of compound B in benzene- methanol at $303 \mathrm{~K} \pm 0.1$ in poise

\begin{tabular}{ccccc}
\hline \multicolumn{5}{c}{ Volume \% of methanol } \\
\hline Conc & $40 \%$ & $60 \%$ & $80 \%$ & $100 \%$ \\
\hline 0.0002 & 0.592 & 0.568 & 0.549 & 0.529 \\
0.0004 & 0.607 & 0.585 & 0.565 & 0.542 \\
0.0006 & 0.619 & 0.596 & 0.575 & 0.551 \\
0.0008 & 0.624 & 0.601 & 0.577 & 0.555 \\
0.0010 & 0.630 & 0.607 & 0.582 & 0.559 \\
0.0012 & 0.638 & 0.616 & 0.588 & 0.564 \\
0.0014 & 0.647 & 0.624 & 0.593 & 0.567 \\
\hline
\end{tabular}

Table -3 . Viscosity, $\eta$, of compound $\mathrm{C}$ in benzene- methanol at $303 \mathrm{~K} \pm 0.1$ in poise

\begin{tabular}{ccccc}
\hline \multicolumn{5}{c}{ Volume \% of methanol } \\
\hline Conc & $40 \%$ & $60 \%$ & $80 \%$ & $100 \%$ \\
\hline 0.0002 & 0.591 & 0.571 & 0.551 & 0.533 \\
0.0004 & 0.614 & 0.593 & 0.569 & 0.546 \\
0.0006 & 0.627 & 0.606 & 0.581 & 0.559 \\
0.0008 & 0.632 & 0.610 & 0.586 & 0.565 \\
0.0010 & 0.639 & 0.616 & 0.593 & 0.570 \\
0.0012 & 0.646 & 0.620 & 0.596 & 0.573 \\
0.0014 & 0.651 & 0.629 & 0.600 & 0.576 \\
\hline
\end{tabular}

Table -4 . Viscosity, $\eta$, of compound $\mathrm{D}$ in benzene-methanol at $303 \mathrm{~K} \pm 0.1$ in poise

\begin{tabular}{ccccc}
\hline \multicolumn{5}{c}{ Volume \% of methanol } \\
\hline Conc & $40 \%$ & $60 \%$ & $80 \%$ & $100 \%$ \\
\hline 0.0002 & 0.596 & 0.573 & 0.553 & 0.535 \\
0.0004 & 0.621 & 0.595 & 0.573 & 0.551 \\
0.0006 & 0.635 & 0.609 & 0.587 & 0.564 \\
0.0008 & 0.641 & 0.615 & 0.592 & 0.568 \\
0.0010 & 0.647 & 0.621 & 0.596 & 0.571 \\
0.0012 & 0.652 & 0.627 & 0.599 & 0.573 \\
0.0014 & 0.658 & 0.634 & 0.602 & 0.578 \\
\hline
\end{tabular}


The increase in viscosity with the increase in concentration may be due to the increasing tendency of molecules to associate in the form of clustering entity in the solvent system. The numbers of workers have reported the molecular interaction and characterizing aspects of physicochemical behavior of binary liquid mixtures and mixed solvent. ${ }^{13}$ The difference in the viscosities of solutions in varying composition of benzenemethanol mixtures is mainly due to the difference in the viscosities of the solvent mixtures. The plots of viscosity $(\eta)$ against concentration (C) are characterized by an intersection of two straight lines at a definite concentration corresponding to TCP of the molecule (Fig.1-4).
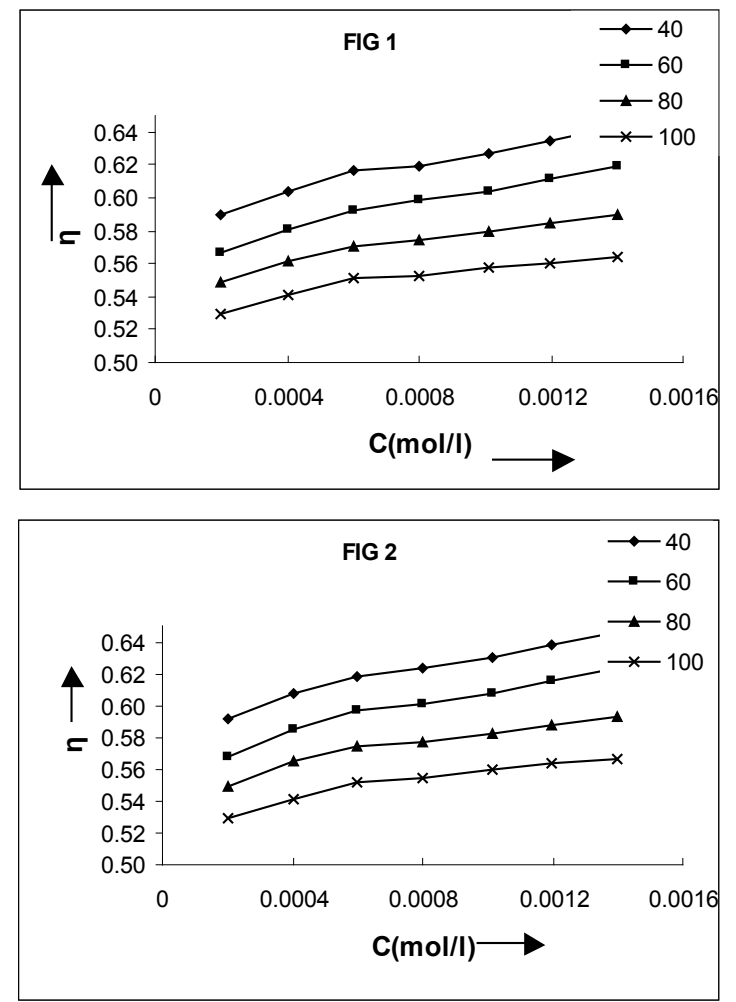
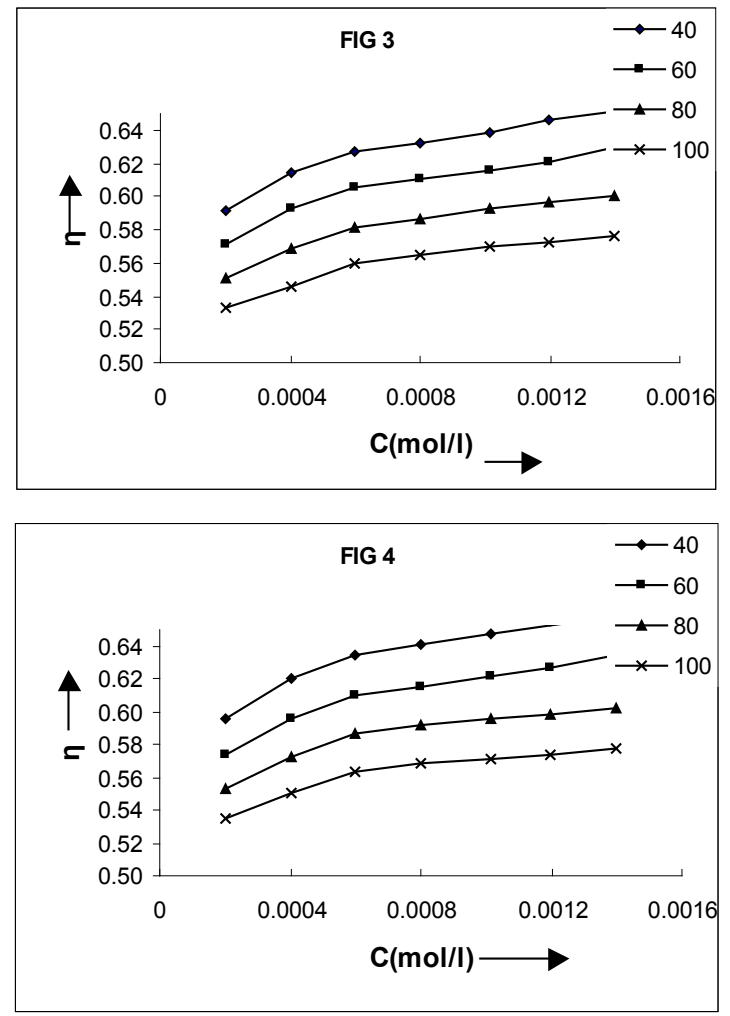

Fig. 1-4 Plot of $\eta$ versus $C$ for compound A-D in benzene-methanol.

Of course this is the maximum concentration of molecular dispersion where balancing of the internal forces causes the formation of aggregates. It is apparent from the data that the values of TCP are dependent on the composition of solvent mixtures. The values of TCP in the solution containing benzene below 50\% are lower as compared to those containing higher volume percent of benzene. This may be attributed to the change in the mobility of the molecules due to change in the dielectric constant of the solvent mixture having different composition of benzene-methanol. Further it is suggested that predominance of lipophilic character in the solvent mixture plays a pertinent role in the clustering alignment of the solute molecules. Thus there is delay in the aggregation due to increase in the interaction between lipophilic solvent and solute molecules. The viscosity of solutions as well as those of the solvent mixtures increases as the volume percent 
of benzene increases which may be attributed to the cumulative effect of the variation of dielectric constant, degree of aggregation and the nature of the agglomerate.

The values of specific viscosity $\left(\eta_{\mathrm{sp}}\right)$ of solutions in varying compositions of benzene-methanol mixtures also increase with the increase in the concentration.
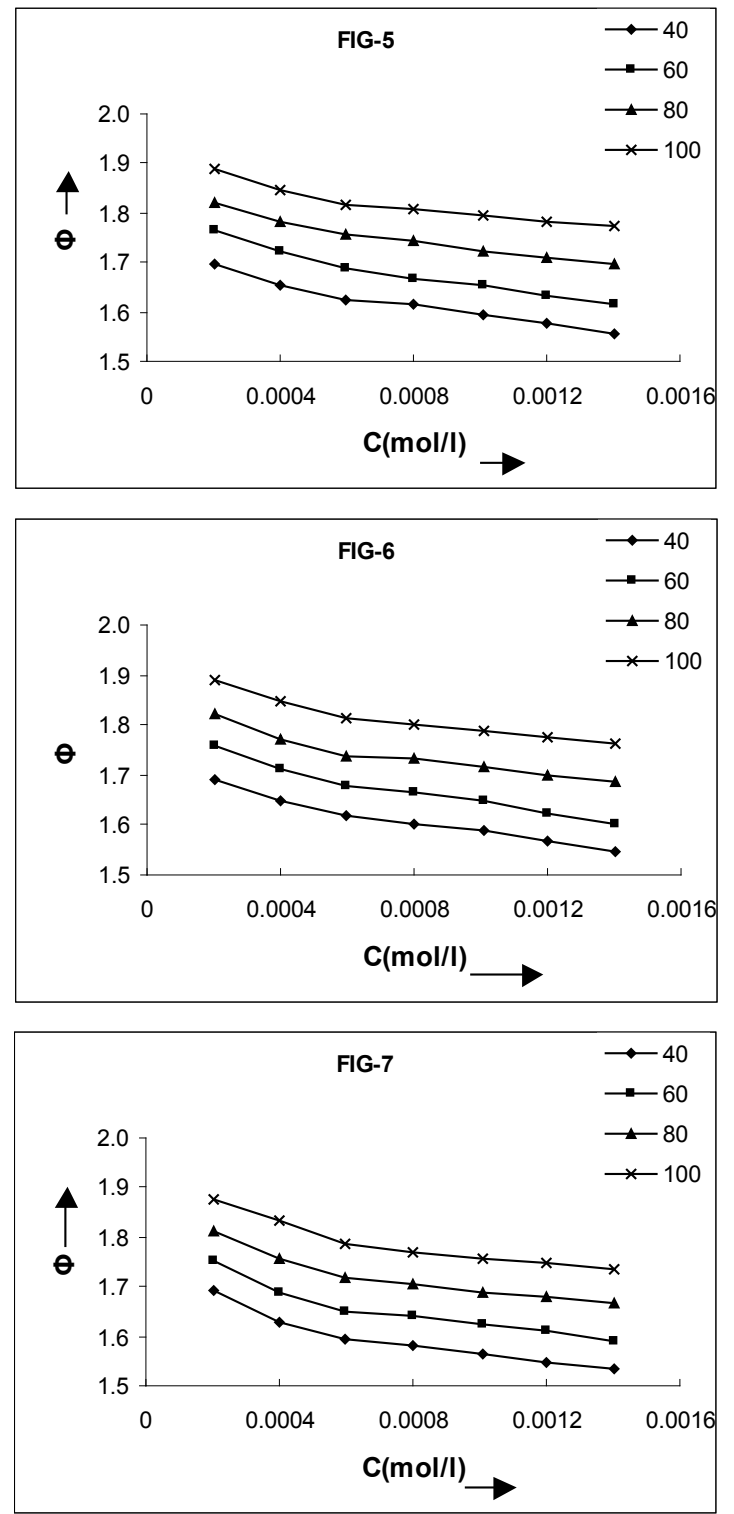

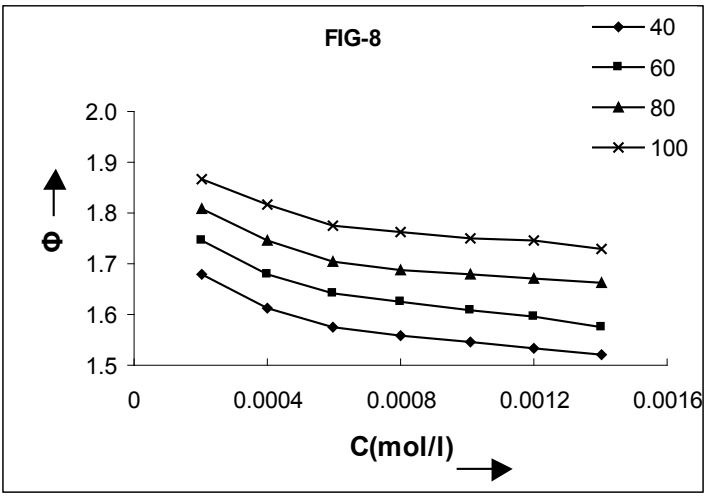

Fig. 5-8 Plots of $\phi$ versus $C$ for vompound A-D in benzene-methanol.

The nature of curves and TCP values are in good agreement with those observed for viscosity data. The fluidity of solutions in benzenemethanol mixtures decreases with the increase in the concentration as well as with the increase in volume percent of benzene (Fig. 3). A perusal of Table- 2 indicates that TCP values are in good agreement with those derived from viscosity and specific viscosity curves and are dependent on the solvent composition.

The viscosity results have been explained in terms of equations proposed by Einstein ${ }^{14}$ and Vand. ${ }^{15}$

Einstein: $\eta_{\mathrm{sp}}=2.5 \mathrm{~V} \mathrm{C}$

Vand: $1 / C=(0.921 / V) \times\left[1 / \log \left(\eta / \eta_{0}\right)\right]+Q V$

Where $\mathrm{V}, \mathrm{C}, \mathrm{Q}, \eta, \eta_{0}$ and $\eta_{\mathrm{sp}}$ are molar volume, concentration, interaction coefficient, viscosity of the solution, viscosity of solvent and specific viscosity respectively. The plots of specific viscosity $\left(\eta_{\mathrm{sp}}\right)$ against concentration $(C)$ are characterized by an intersection of two straight lines at a definite concentration, which corresponds to the TCP. The plots with intercept almost equal to zero are linear below TCP, which shows that the equation proposed by Einstein are applicable to dilute solutions. ${ }^{16}$ It is observed that the values of molar volume V obtained from the plots of Einstein equation and Vand equation. 
Table - 5. Values of molar volume (V) in benzene - methanol derived from Einstein and Vand equations compound \%of methanol Einstein equation Vand equation

\begin{tabular}{|c|c|c|c|c|c|}
\hline & & & & & \\
\hline & & $\mathrm{V}_{1}$ & $\mathrm{~V}_{2}$ & $\mathrm{~V}_{1}$ & $\mathrm{~V}_{2}$ \\
\hline \multirow[t]{4}{*}{ compound A } & $40 \%$ & 47.6600 & 27.7372 & 80.3960 & 53.9520 \\
\hline & $60 \%$ & 48.2680 & 24.8596 & 68.5360 & 59.0760 \\
\hline & $80 \%$ & 38.7288 & 19.1484 & 74.9440 & 51.6160 \\
\hline & $100 \%$ & 42.0640 & 14.0272 & 55.5680 & 48.3600 \\
\hline \multirow[t]{4}{*}{ compound B } & $40 \%$ & 46.7800 & 26.7800 & 93.2760 & 59.1720 \\
\hline & $60 \%$ & 51.7280 & 28.4644 & 75.4320 & 56.8120 \\
\hline & $80 \%$ & 48.3360 & 19.5212 & 72.6560 & 55.5640 \\
\hline & $100 \%$ & 42.8600 & 15.5160 & 56.5880 & 50.6400 \\
\hline \multirow[t]{4}{*}{ compound $\mathrm{C}$} & $40 \%$ & 63.7520 & 22.6224 & 92.9160 & 77.2280 \\
\hline & $60 \%$ & 63.7520 & 22.6224 & 84.0840 & 75.8240 \\
\hline & $80 \%$ & 56.4240 & 16.6068 & 80.4800 & 71.1320 \\
\hline & $100 \%$ & 51.2000 & 14.3560 & 71.6560 & 66.2600 \\
\hline \multirow[t]{4}{*}{ compound D } & $40 \%$ & 68.5840 & 19.0068 & 106.9400 & 88.4320 \\
\hline & $60 \%$ & 65.9360 & 23.5528 & 96.2720 & 82.1600 \\
\hline & $80 \%$ & 63.5680 & 11.9428 & 86.6320 & 81.6600 \\
\hline & $100 \%$ & 55.4640 & 12.4064 & 83.2640 & 71.3760 \\
\hline
\end{tabular}

It is interesting to note that the values of molar volume enumerated from these equations are almost equal and the trend remains unaltered irrespective of the type of equation applied.
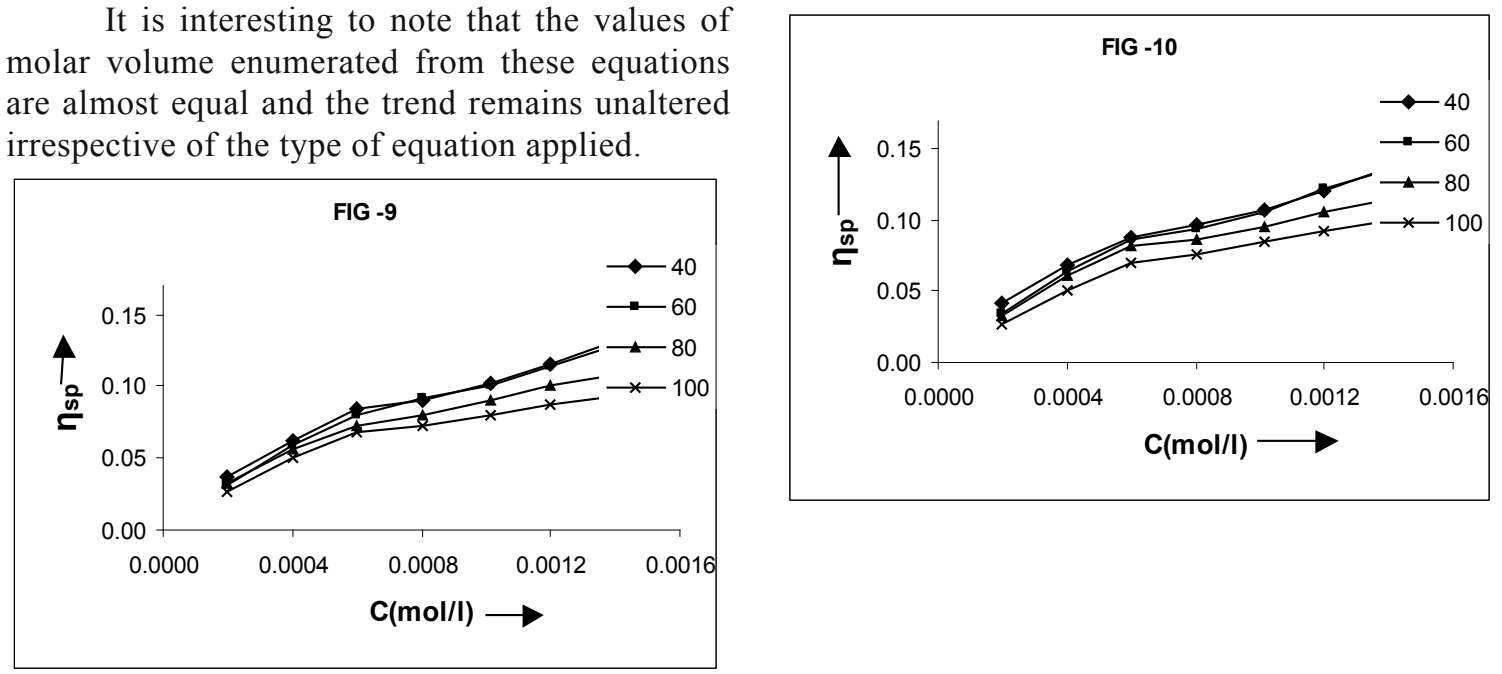

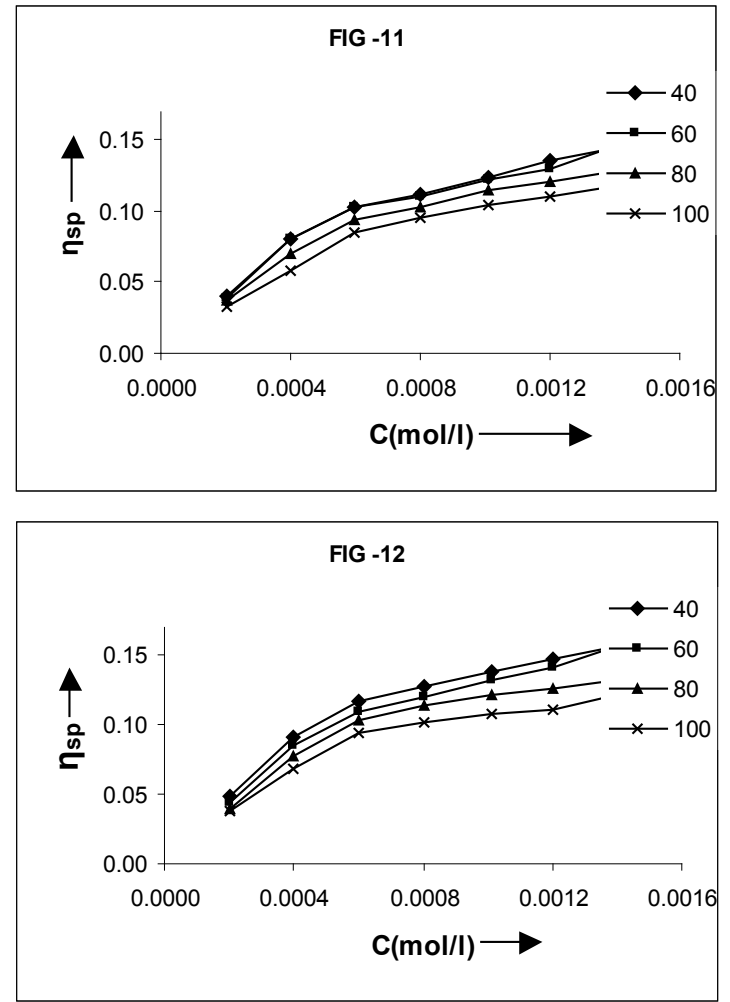

Fig. 9-12 Plot of $\eta_{\text {sp }}$ versus $C$ for compound A-D in benzene-methanol.

The Moulik equation. ${ }^{17}$ also fits well to the solutions, as the plots $\left(\eta / \eta_{0}\right)^{2}$ vs. $C^{2}$ are almost linear.

$\left(\boldsymbol{\eta} / \boldsymbol{\eta}_{0}\right)^{2}=\mathbf{M}+\mathbf{K C}^{2}$

Where $\mathrm{M}$ and $\mathrm{K}$ are constants.

The values of $\mathrm{M}$ and $\mathrm{K}$ have been calculated from the intercepts and slopes of the $\left(\eta / \eta_{0}\right)^{2}$ vs. $\mathrm{C}^{2}$ plots and are recorded in Table- 6 .

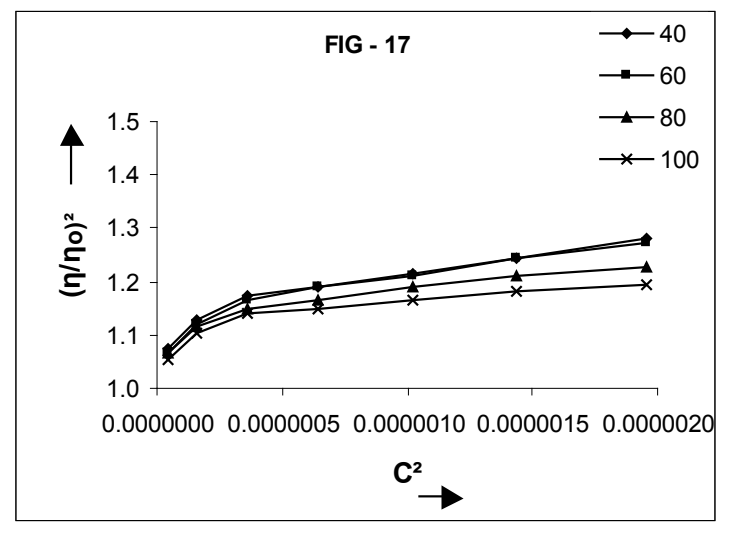

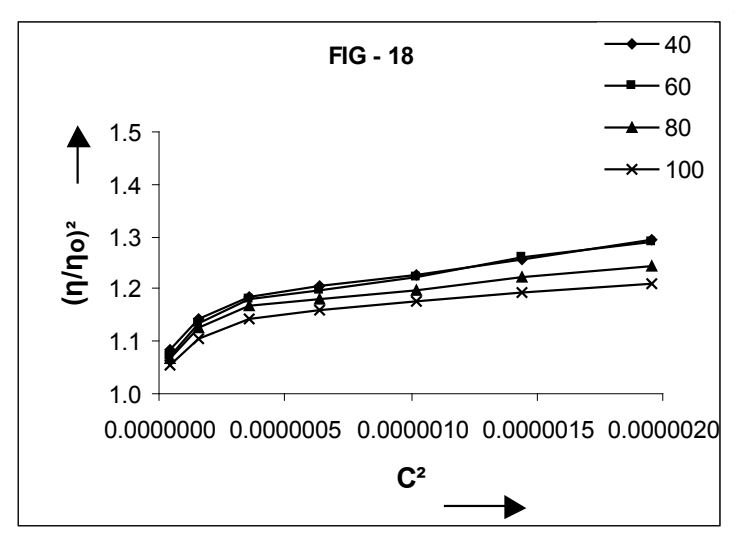
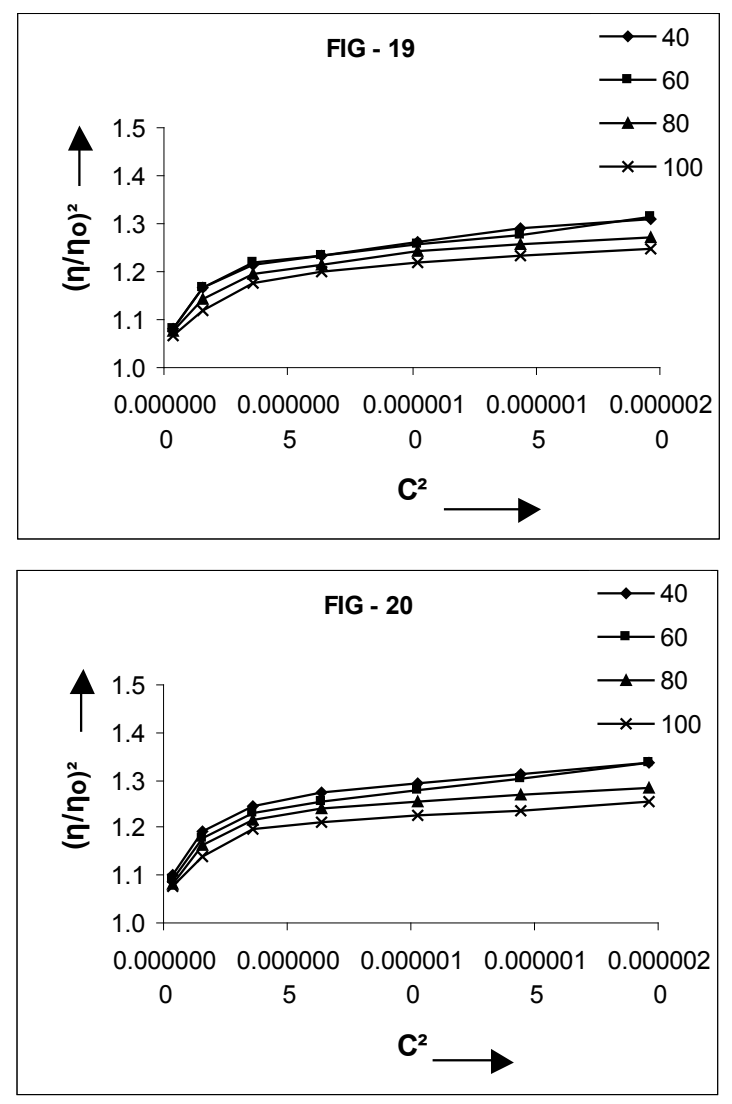

Fig.17-20 Plot of $\left[\eta / \eta_{0}\right]^{2}$ versus $C^{2}$ for compound A-D in benzene-methanol.

The viscosity data have also been interpreted in the light of Jones-Dole equation. ${ }^{18}$

$\left(\boldsymbol{\eta} / \boldsymbol{\eta}_{\mathbf{0}}-\mathbf{1}\right) / \sqrt{ } \mathbf{C}=\mathbf{A}+\mathbf{B} \sqrt{ } \mathbf{C}$

For convenience, the equation may be expressed as $\boldsymbol{\psi} / \sqrt{ } \mathbf{C}=\mathbf{A}+\mathbf{B} \sqrt{ } \mathbf{C}$ 
Where the coefficient A and B refer to solute-solute and solute-solvent interactions respectively. The plots $\psi / \sqrt{ } \mathrm{C}$ vs. $\sqrt{ } \mathrm{C}$
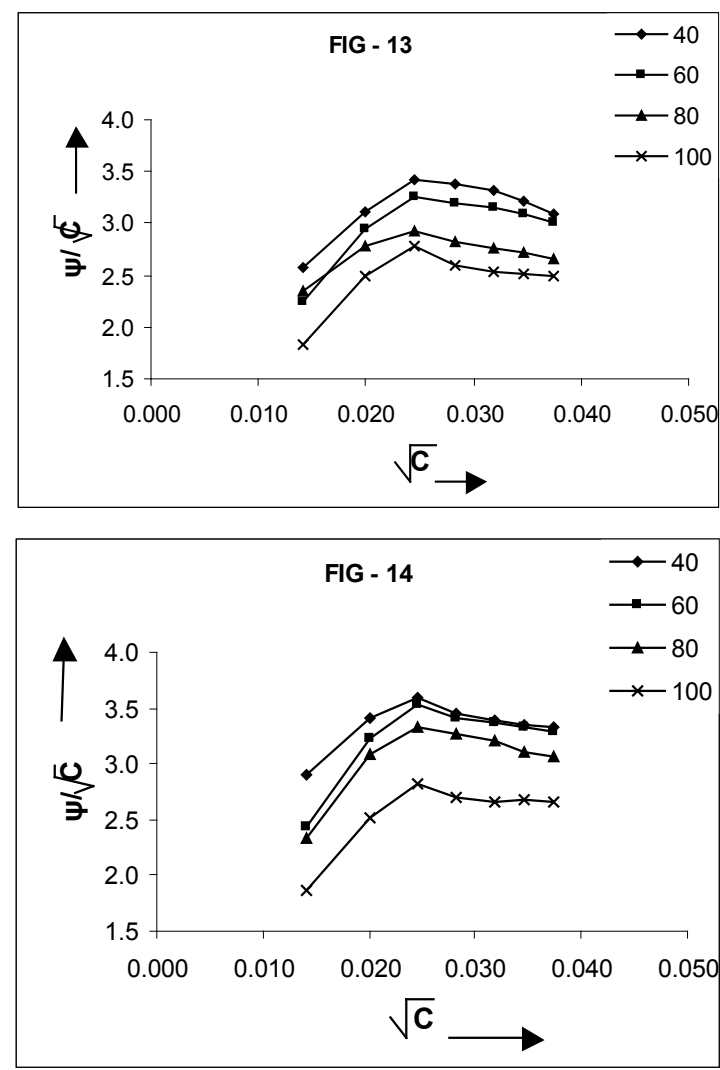
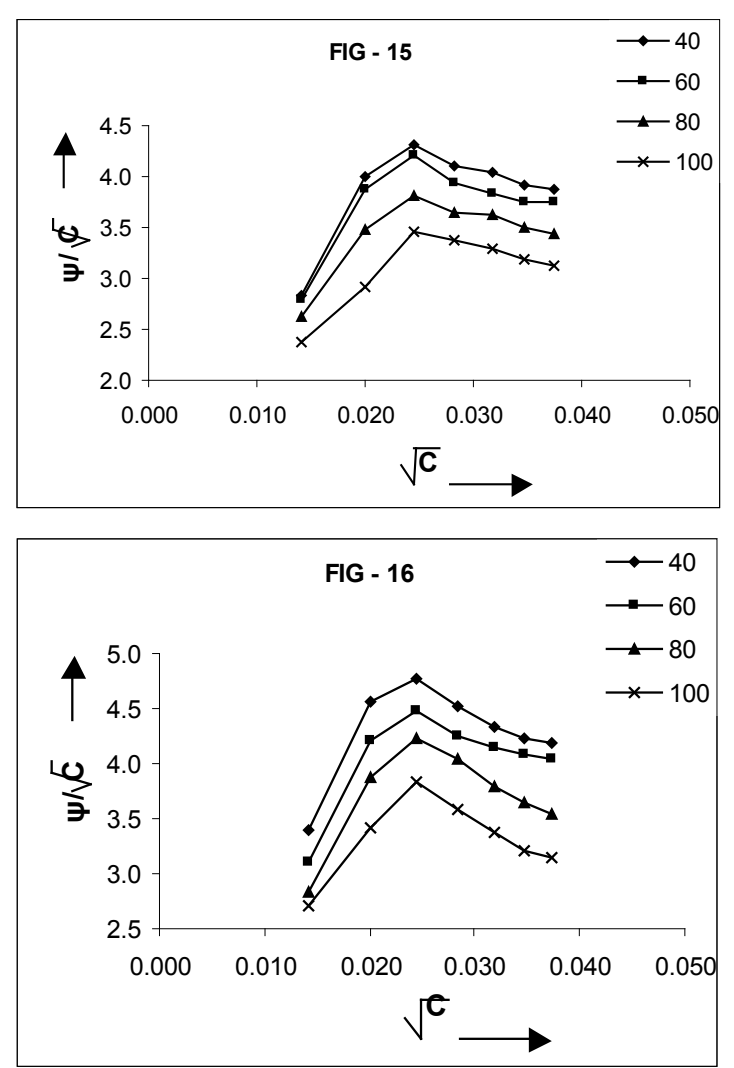

Fig.13-16 Plot of $\psi / \sqrt{ } \mathrm{C}$ versus $\sqrt{ } \mathrm{C}$ for compound A-D in benzene-methanol.

for the molecules studied here were found to be linear, with least scatter. These plots are characterized by two straight lines intersecting at a point corresponding to the TCP of compounds. The values of TCP are in good agreement with the values derived from the plots of $\eta, \eta_{\mathrm{sp}}$ and $\phi$ vs. C. In view of the two intersecting straight lines for $\psi$ $/ \sqrt{ } \mathrm{C}$ vs. $\sqrt{ } \mathrm{C}$ plots, it is logical to evaluate two values of both the coefficients below and above TCP designated as $A_{1}, B_{1}$ and $A_{1}, B_{1}$ respectively. 
Table -6 . Viscosity parameters in benzene - methanol derived from different equations

\begin{tabular}{cccccccccc}
\hline \multicolumn{2}{c}{$\begin{array}{c}\text { compound \% of } \\
\text { methanol }\end{array}$} & \multicolumn{4}{c}{ Moulik equation } & \multicolumn{4}{c}{ Jones-Dole equation } \\
\cline { 2 - 9 } \multicolumn{2}{c}{$\mathbf{M}_{\mathbf{1}}$} & $\mathbf{M}_{2}$ & $\mathbf{K}_{1}$ & $\mathbf{K}_{2}$ & $\mathbf{A}_{1}$ & $\mathbf{A}_{2}$ & $\mathbf{B}_{1}$ & $\mathbf{B}_{2}$ \\
\hline compound A & $40 \%$ & 1.069 & 1.143 & 307187 & 70036 & 1.407 & 2.102 & 83.566 & 36.505 \\
& $60 \%$ & 1.060 & 1.150 & 308995 & 62869 & 0.861 & 2.430 & 99.986 & 25.952 \\
& $80 \%$ & 1.064 & 1.139 & 246195 & 47155 & 1.552 & 2.587 & 58.107 & 8.589 \\
& $100 \%$ & 1.049 & 1.130 & 266636 & 34176 & 0.568 & 2.742 & 92.133 & -6.651 \\
compound B & $40 \%$ & 1.080 & 1.159 & 301055 & 68177 & 1.995 & 2.666 & 66.859 & 25.271 \\
& $60 \%$ & 1.066 & 1.152 & 331527 & 71956 & 1.003 & 2.268 & 105.700 & 36.054 \\
& $80 \%$ & 1.064 & 1.150 & 308373 & 48528 & 1.029 & 2.884 & 96.627 & 4.645 \\
& $100 \%$ & 1.049 & 1.137 & 272615 & 37966 & 0.581 & 2.804 & 93.413 & -3.860 \\
& & & & & & & & & \\
compound C & $40 \%$ & 1.078 & 1.202 & 409288 & 57418 & 0.877 & 4.100 & 144.87 & -5.829 \\
& $60 \%$ & 1.078 & 1.197 & 409288 & 58197 & 0.898 & 4.496 & 139.79 & -20.573 \\
& $80 \%$ & 1.071 & 1.195 & 363636 & 41453 & 1.018 & 4.349 & 117.09 & -24.338 \\
& $100 \%$ & 1.059 & 1.180 & 333095 & 35690 & 0.866 & 4.350 & 104.72 & -27.271 \\
& & & & & & & & & \\
compound D & $40 \%$ & 1.096 & 1.243 & 445140 & 49099 & 1.610 & 5.564 & 134.880 & -37.644 \\
& $60 \%$ & 1.086 & 1.217 & 427059 & 60826 & 1.271 & 4.865 & 136.160 & -22.329 \\
& $80 \%$ & 1.077 & 1.224 & 411421 & 30275 & 0.966 & 5.589 & 137.170 & -55.580 \\
& $100 \%$ & 1.071 & 1.193 & 359936 & 31496 & 1.193 & 4.977 & 108.730 & -49.811 \\
\hline
\end{tabular}

It is observed that the values of these constants depend on the composition of the solvent mixtures.

\section{CONCLUSION}

It has been observed that the viscosity of the system increases with the increase in concentration. The increasing trend of viscosity may be due to combined effect of the variation of dielectric constant of solvent, degree of aggregation and nature of the compound agglomerate. The TCP values obtained from different viscosity data are in good agreement and show maximum concentration of molecular dispersion at which aggregation of molecule initiates.

It is noteworthy to point out on the basis of results obtained that the above treatment gives a phenomenological description of clustering profile and confirms the existence of aggregation in the non-aqueous mixed solvent.

\section{References:}

[1] M.Gracia, Valverde and T. Torroba, Molecules, 10 (2005) 318.

[2] C. O. Kappe, Terahedron, 49 (1993) 6937.

[3] T. Matsuda, J. Hirao, Nippon Kagaku Zasshi, 86 (1965) 1195.

[4] Birgit Jauk, Tetiana Pernat and C. O. Kappe, Molecules. 5 (2000) 227.

[5] C. O. Kappe, G. Farber, J. Chem. Soc., Perkin Trans, 1 (1991) 1342.

[6] Y. S. Sadanandam, M. M. Shetty, P. V. Diwan, Eur. J. Med. Chem.27 (1992) 87.

[7] (7a) S. Sukemi, H. J. Sun, Org. Chem. 56 (1991) 4304. (7b) Y. Kawasaki, M. Yamashita, S. Otha, Chem. Pharma Bull. 44 (1996) 1831.

[8] Mieczyslaw, Makosza, Pure \& Appl. Chem. 69(3) (1997) 559.

[9] K. Lee, S. J. Moon, D. C. Ha, Kee- In Lee; Y.D. Gong, and J. C. Lee, Bull Korean Chem. Soc. 27 (2006) 7.

[10] (10a) J. Thesing, G. Sembler, and G. Mohr, Chem. Ber. 95 (1962) 2205. (10b) G. W. Gribble, C. F. Nutaitis, Org. Prep. Proc. Int. 17 (1985) 317. 
[11] M. Duflos, Marie - Renee J. Nourrisson, J. Brelet, Courant, Guillaume Le Baut, N. Grimoud, Jean - Yves Petit.; Eur. J. Med. Chem. 36 (2001) 545.

[12] (12a) D. S. Bose, L. Fatima, H. B. Mereyala, J. Org. Chem. 68 (2003) 587. (12b) J. Lu, Y. Bai, Synthesis (2002) 466.

[13] H. Suzuki, Journal of American Oil Chemists Society 47 (1969) 273. (13b) K.N. Mehrotra, V.P. Mehta, T.N. Nagar, Journal fur Praktische Chemie 312 (4) (1970) 545. (13c) R.P. Verma, K. Singh, H. Singh, Annali di chimica 68(5) (1978) 415. (13d) V.P. Mehta, M. Hasan, L.C. Heda, Afinidad 39 (1982) 385.

[14] A. Einstein, Annalen der Physik 19 (1906) 289.

[15] V. Vand, Journal Physical Colloid Chemistry 52 (1948) 277.

[16] K.N. Mehrotra, K. Tandon, M.K. Rawat, Journal of the Indian Chemical Society 69 (1990) 719.

[17] S.P. Moulik, The Journal of Physical Chemistry 72 (1968) 4682.

[18] G. Jones, M. Dole, The Journal of The American Chemical Society 51 (1929) 2950. 